\title{
HIV/AIDS, HUMAN RIGHTS AND INSURANCE - SOME INDICATORS
}

\section{Elsabe Klinck}

Legal Adviser, South African Medical Association Human Rights, Law and Ethics Unit

Every patient has a constitutional right to privacy and every doctor has an ethical duty to maintain patient confidentiality. The principle is that any third party such as an insurance company can only access information to which a patient (the insured) has provided informed consent. Informed consent means that the person is aware of the consequences of his/her consent. Therefore the South African Medical Association does not regard blanket consent or consent obtained years ago as informed consent. In insurance law, a person (the insured) has to disclose all material facts that may affect the insurance to the insurer. The relationship is between the insurer and the insured, and unless the insured has consented to the medical practitioner making medical information known on his/her behalf, the practitioner is bound to preserve confidentiality. The family of a deceased person may consent to an insurer requesting information from the practitioner in terms of the Promotion of Access to Information Act of 2000 . The Regulations to the Act must be used to request the information.

Medical practitioners may be requested to complete forms in which they have to indicate their suspicions in relation to a patient's HIV status. If the doctor does not know a deceased person's HIV status, it cannot be revealed, because one cannot reveal what one does not know. If disclosure of medical facts (or indicators) is required ex post facto, companies and others may require a range of tests to be performed on deceased persons, but again that is something that has to be contractually agreed between the insurer and the insured when the policy is taken out.

Insurance companies aim to be profitable and work on collective risk. With the coming into operation of the Promotion of Equality and Prevention of Unfair Discrimination Act later this year, insurance companies may be required to justify HIV exclusions. HIV status is a socalled 'additional prohibited ground' of discrimination and the schedule to the Act lists the following as illustrations of unfair practices:

(a) Unfairly refusing on one or more of the prohibited grounds to provide or to make available an insurance policy to any person.

(b) Unfair discrimination in the provision of benefits, facilities and services related to insurance.

(c) Unfairly disadvantaging a person or persons, including unfairly and unreasonably refusing to grant services to persons, solely on the basis of HIV/AIDS status.'

Aggrieved individuals or the family members of deceased persons may approach their nearest Magistrate's Court to enforce these statutory rights. Insured persons should also be aware that insurers may contest pay-outs or insurance claims on the basis of the non-disclosure of material facts, and such claims may even be made against a deceased person's estate. 